\title{
Oxaliplatin-induced Autoimmune Hemolitic Anemia
}

\section{Oksaliplatine Bağlı Otoimmün Hemolitik Anemi}

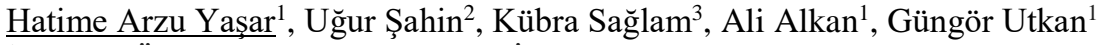 \\ ${ }^{1}$ Ankara Üniversitesi Tıp Fakültesi İç Hastalıkları Anabilim Dalı, Tıbbi Onkoloji Bilim Dalı, Ankara, Türkiye \\ ${ }^{2}$ Ankara Üniversitesi Tıp Fakültesi İç Hastalıkları Anabilim Dalı, Hematoloji Bilim Dalı, Ankara, Türkiye \\ ${ }^{3}$ Ankara Üniversitesi Tıp Fakültesi İç Hastalıkları Anabilim Dalı, Ankara, Türkiye \\ Dergiye Ulaşma Tarihi:30.03.2016 Dergiye Kabul Tarihi:02.03.2017 Doi: 10.5505/aot.2017.07269
}

\section{ÖZET}

Oksaliplatin, onkoloji pratiğinde sık kullanılan üçüncü kuşak bir platin analoğudur. En sık görülen yan etkileri arasında bulantı, kusma, diyare, nöropati ve kemik iliği baskılanması yer almaktadır. İmmüntrombositopeni ve immün hemolitik anemi seyrek olarak bildirilmektedir. Bu yazıda, oksaliplatin ilişkili otoimmün hemolitik anemi (OİHA) gelişen bir olgu ve tedavi yaklaşımı tartışılmaktadır. Metastatik kolon kanseri tanısı ile izlenen hasta, oksaliplatin içeren bir kemoterapi protokolünü takiben başlayan kırmızı renkli idrar yapma şikâyeti ile acil servise başvurdu. Hastanın başvurusunda derin anemisi ve retikülositozunun olduğu ve serum biyokimyasının hemoliz ile uyumlu olduğu görüldü. Direk ve indirek Coombs testleri de pozitif olarak bulunan hastaya OİHA tanısı kondu. Oksaliplatinin kesilmesi ve kortikosteroid ve plazmaferez tedavisini takiben hemolizde düzelme izlendi. Oksaliplatin göreceli olarak iyi bir yan etki profiline sahip olmakla birlikte, daha seyrek görülen, ancak şiddetli seyredebilecek immün ilişkili yan etkileri gözden kaçırılmamalıdır.

Anahtar Kelimeler: otoimmün hemolitik anemi, oksaliplatin, kolorektal kanser

\begin{abstract}
Oxaliplatin is a third-generation platinum derivative, commonly used in the practice of oncology. The usual side effects include nausea, vomiting, diarrhea, neuropathy and myelosuppression. Oxaliplatin-induced immune thrombocytopenia and immune hemolytic anemia have rarely been reported. Herein, a case of oxaliplatin- induced autoimmune hemolytic anemia(AIHA) and its management have been discussed. The patient with metastatic colorectal carcinoma was admitted to the emergency room with the symptom of reddish coloration of her urine after receiving an oxaliplatin-based regimen. On her admission she had profound anemia with reticulocytosis and a serum biochemistry concordant with hemolysis. The positivity of direct and indirect Coombs tests pointed to the diagnosis of AIHA. Hemolysis improved after discontinuation of oxaliplatin and treatment with corticosteroids and plasmapheresis. Although oxaliplatin has a relatively favorable side effect profile, the possibility of less frequent, but potentially serious immune-related side effects should never be overlooked.
\end{abstract}

Keywords: autoimmune hemolytic anemia, oxaliplatin, colorectal cancer

\section{Giriş}

Oksaliplatin kolorektal kanser (KRK) tedavisinde kullanılan üçüncü kuşak bir platin analoğudur. Kapesitabin (XELOX) ya da folinik asit ve florourasil (FOLFOX) ile birlikte kullanılmaktadır. En s1k görülen yan etkileri bulant1, kusma, diyare, nöropati ve kemik iliği baskılanmasıdır. Daha seyrek olarak uzun süreli kullanımında immüntrombositopeni, hemolitik anemi ve yaygın damar içi pıhtılaşma bildirilmiştir (1-3). İlaca bağlı otoimmün hemolitik anemi (OİHA) nadir görülen, fakat ciddi bir yan etkidir. Oksaliplatin ilişkili OİHA intravasküler hemoliz bulgulariyla seyreden akut bir tabloya sebep olmaktadır (4). Yüksek ve tekrarlanan oksaliplatin dozlarında hemolitik Adress for correspondence: Murat Burç Yazıcıŏlu, Derince Eğitim ve Araştırma Hastanesi Genel Cerrahi Kliniği, Kocaeli - Türkiye e-mail: mbyazicioglu@gmail.com

Available at www.actaoncologicaturcica.com

Copyright CAnkara Onkoloji Hastanesi olayların görülme sıklığı artmaktadır (5). Bu yazıda, metastatik KRK tanısı ile izlenen ve oksaliplatin içeren bir kemoterapi protokolünü takiben OİHA gelişen bir olgu tartışılacaktır.

\section{Olgu}

Diyabetes mellitus dışında bilinen kronik hastalığı olmayan 53 yaşında kadın hasta KRK tanisı ile opere edildikten sonra adjuvan tedavi olarak 6 kür FOLFOX-6 (folinik asit - 5florourasil - oksaliplatin) kemoterapi protokolü verildi. İki y1l süreyle tam remisyonda izlenen hastada karaciğer ve her iki overde metastaz saptanması üzerine total abdominal histerektomi ve bilateral salpingooferektomiyi takiben FOLFİRI (folinik asit - 5-florourasil - 
irinotekan) protokolü başlandı. $\mathrm{Bu}$ tedavi altında hastalı progresyonu gelişmesi nedeniyle XELOX (kapesitabin -oksaliplatin) protokolüne geçildi. XELOX ile de hastalık kontrolü sağlanamaması üzerine hastaya aşağı anterior rezeksiyon, ileostomi ve intraoperatif hipertermik intraperitoneal kemoterapi uygulamas1 yapıld1. Ameliyat1 takiben FOLFOX-6+bevasizumab tedavisi başlandi. Bu tedavinin dördüncü küründe oksaliplatin infüzyonu sırasında hastada hipotansiyon, taşikardi, dispne ve kendiliğinden gerileyen maküler cilt döküntüleri ile seyreden hafif-orta şiddetli bir alerjik reaksiyon izlendi. Beşinci kür tedavisi verildikten bir gün sonra hasta acil servise kırmızı renkli idrar yapma ve bel ağrısı şikayetleri ile başvurdu. Başvurusundaki fizik muayenesinde sarılık dışında herhangi bir pozitif bulgusu, karaciğer ve dalak büyümesi bulunmamaktaydi. Laboratuvar testlerinde hemoglobin: $5,9 \mathrm{~g} / \mathrm{dL}$, lökosit: $30,5 \mathrm{x}$ $10^{9} / \mathrm{L}$, trombosit: $379 \times 10^{9} / \mathrm{L}, \mathrm{MCV}: 86,8 \mathrm{fL}$, retikülosit: 107 x $10^{9} / \mathrm{L} \quad(\% 4,32), \quad$ BUN: $24 \mathrm{mg} / \mathrm{dL}$, kreatinin: $1,21 \mathrm{mg} / \mathrm{dL}, \mathrm{K}^{+}: 5,6 \mathrm{mEq} / \mathrm{L}$, total bilirübin: $10,1 \mathrm{mg} / \mathrm{dL}$, indirekbilirübin: 8,7 $\mathrm{mg} / \mathrm{dL}$, aspartat amino transferaz(AST): 178U/L, alanin amino transferaz (ALT): 24 U/L, laktat dehidrojenaz (LDH): $2022 \mathrm{U} / \mathrm{L}$, haptoglobulin 1,35 g/L (0,36 - 1,95),aPTT: 36,4 san $(25,1-36,5)$, PT: 17,9 san $(9,4-12,5)$, ddimer: $990 \mathrm{ng} / \mathrm{mL}$ (0-243), fibrinojen: $2,86 \mathrm{~g} / \mathrm{L}$ (2-3,93) bulundu. Otomatik idrar analizinde idrarda hemoglobin pozitif bulundu. Ancak idrar mikroskopisinde eritrosit saptanmad. Hastanın çevre kanı yaymasında sferositler ve makrositler görüldü. Şistosit izlenmedi (Şekil1). Serolojik testlerde EBV, HSV, CMV'ye ilişkin akut enfeksiyon; HBV ve HCV'ye ilişkin kronik enfeksiyon bulgusu saptanmadi. En düşük hemoglobin değeri kemoterapinin üçüncü gününde $4,9 \mathrm{~g} / \mathrm{dL}$ olarak ölçüldü (Şekil2). Hastanın izleminde total bilirübin $18,1 \mathrm{mg} / \mathrm{dL}$, indirek bilirübin $12,6 \mathrm{mg} / \mathrm{dL}$ 'ye kadar yükseldi. Direk Coombs testinde hasta eritrositlerinin anti-IgG için 3+ ve anti-C3d için $4+$ tepkime verdiği izlendi. Soğuk aglütinin testi negatif bulundu. İndirek Coombs testinde 1., 2. ve 3 . test hücrelerinin sirasiyla $1+, 2+$ ve $2+$; otokontrolün $3+$ tepkime verdiği görüldü. $\mathrm{Bu}$ sonuç hastanın kanında hem allo-antikor, hem de oto-antikor bulunması olarak yorumland. Antikor tanımlanma testinde sonuç elde edilemedi. Hastaya son 1 y1l içinde hiçbir kan ürünü transfüzyonu yapılmamıştı. Obstetrik öyküsünden iki kez doğum yaptığı öğrenildi. Bilinen bir otoimmün hastalığı olmayan ve sürekli kullanmakta olduğu başka bir ilaç bulunmayan hastada ortaya çıkan OİHA tablosu mevcut bulgular ve hemolitik aneminin ortaya çıkış süresi de göz önünde bulundurulduğunda öncelikle hastanın almış olduğu kemoterapi ile ilişkilendirildi. Hastaya $1 \mathrm{mg} / \mathrm{kg} /$ gün dozunda metilprednizolon tedavisi başlandı. Derin ve semptomatik anemisi olmasi nedeniyle kemoterapi sonrası üçüncü, dördüncü ve yedinci günlerde terapötik aferez işlemi uygulandı. Eritrosit süspansiyonları ile transfüzyon desteği verildi (Şekil-2). Steroid tedavisi sonrası hizlı yanıt alınan hastada kemoterapi sonras1 beşinci günde $\mathrm{LDH}$ değerleri normal seviyelere döndü. İndirek hiperbilirubinemi gerilemeye ve hemoglobin düzeyleri yükselmeye başladı (Şekil-2). Hasta tedavinin onuncu gününde taburcu edildi. Tedavinin birinci ayında direk Coombs testinin negatifleştiği görüldü. Hastanın almakta olduğu steroid tedavisi 2 ay içinde tedricen azaltılarak kesildi. Hastaya bundan sonraki tedavilerinde oksaliplatin verilmedi. Hastanın 10 aylık takibi süresince OİHA nüksü gözlenmedi.

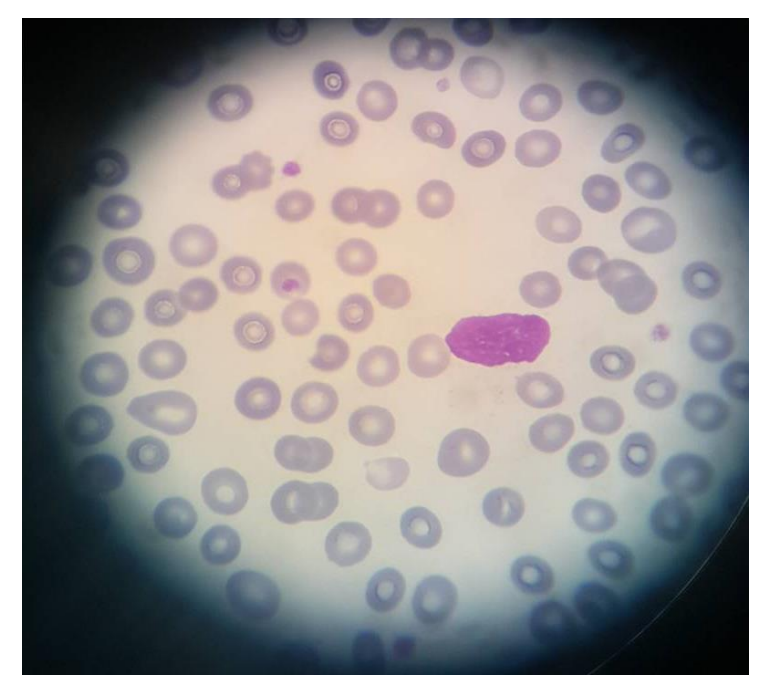

Şekil 1: Hastanın tanı anındaki çevre kanı yaymasında sferositler ve polikromazi (x1000 büyütme). 
墔䩀

1223445677899101112131415

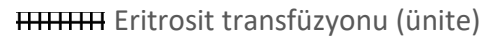

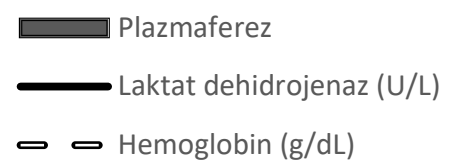

Şekil 2: Hastada kemoterapi gününden başlayarak hemoglobin ve laktatdehidrojenaz (LDH) düzeylerinin seyri.

\section{Tartışma}

İlaç ilişsili OİHA'nın yıllık insidansı yaklaşık olarak milyonda 1-4 olarak bildirilmektedir (6). Nadir görülmekle birlikte ciddi oranda morbidite ve mortaliteye sebep olabilmektedir (6-9). Günümüze kadar 130'dan fazla ilacın OİHA ile ilişkili olduğu bildirilmiştir $(6,10)$. Yakın zamanda Almanya'dan bildirilen ve 73 olguyu içeren bir seride oksaliplatin, ilaç ilişkili OİHA'ya sebep olan ilaçlar arasında sıklık olarak diklofenak, piperasilin ve seftriaksonu takiben dördüncü sırada yer almıştır (6).

Ürtiker, kaşıntı ve anjiyoödem gibi tip I veya $\operatorname{IgE}$ aracılı aşırı duyarlılık tepkimeleri oksaliplatin kullanımı sonras1 hastaların yaklaşık olarak \%10'unda izlenmekte ve genellikle en az beş kürlük tedavi sonrası ortaya çıktıları bildirilmektedir (11). Daha az sıklıkla görülen ve immüntrombositopeni ve immünhemolitik anemiyi içeren tip II tepkimeler de tekrarlanan oksaliplatin infüzyonları sonrasında ortaya çıkmaktadır $(5,12)$. Bizim olgumuzda da dördüncü kür tedavi sonrasında tip I aşırı duyarlılık tepkimesi gözlenmiş olup beşinci kür sonrasında da OİHA gelişmiştir.

İlaç ilişkili immünsitopeni gelişiminde dört hipotez kabul görmektedir: i) hapten oluşumu; ii) immün kompleks oluşumu; iii) otoimmünite; iv) ilaç etkisiyle çeşitli proteinlerin immün olmayan yollarla eritrosit membranına absorpsiyonu (10). İlaç ilişkili OİHA'ya ilaca bağıml antikorlar veya otoantikorlar sebep olabilmektedir. Daha sik olarak görülen ilaca bağımlı antikorlar, sadece ilaç varlığında etki gösterip genellikle kompleman aracilı intra-vaskülerhemoliz ile ani eritrosit yıkımına sebep olurken daha seyrek görülen otoantikorlar, genellikle $\mathrm{Fc}$ aracilı ekstra-vasküler hemoliz ile daha yavaş ve kademeli olarak eritrosit y1kımına yol açmaktadır (6). Bazı ilaçlar her iki tip antikorun birlikte üretilmesine sebep olabilmektedir (10). Oksaliplatin ilişkili OİHA ilk kez 1999'da oksaliplatin infüzyonu sonras1 akut intravasküler hemoliz gelişen bir olguda bildirilmiş ve patogenezinde oksaliplatin bağımlı IgG tipi sıcak aglütininlerin tetiklediği immün kompleks ilişkili hemoliz sorumlu tutulmuştur (9). Oksaliplatinin çeşitli proteinlerin immün olmayan yollarla eritrosit membranına adsorpsiyonuna yol açarak OİHA'ya sebep olduğu düşünülmektedir (8). İlaç ilişskili OİHA varlığında direk Coombs testinde sadece anti-IgG veya sadece anti-C3 ile pozitif olabileceği gibi her ikisinde de pozitiflik görülebilmekte ve serolojik yöntemlerle idiyopatik sıcak hemolitik anemi ve ilaç ilişkili OİHA tanısının ayrımı kesin olarak yapılamamaktadır (8). Kesin tanı için gerekli olan ilaç bağımlı antikorların tanımlanması özel laboratuvar yöntemleri ve tecrübe gerektirdiğinden günlük klinik uygulamada sınırlı kullanım alanına sahiptir (8).

Olgumuzda antikor tanımlamas1 yapılamadığından oksaliplatin ilişkili OİHA için kesin bir tanıdan söz edilememektedir. Oksaliplatin oto-antikor oluşumunadaha seyrek olarak sebep olmaktadır. Bu sebeple hastanın indirek Coombs testinde izlenen oto-antikor pozitifliği öncelikle idiyopatik sıcak OİHA tanısını düşündürebilir. Ancak hastanın hikayesinde bulunan tekrarlanan oksaliplatin uygulamalarının ardından ilacın infüzyonu sonrası akut olarak gelişen şiddetli intravasküler hemoliz ve direk Coombs pozitifliği, oksaliplatin ilişkili OİHA tanısı için önemli ipuçlarıdır. İndirekCoombs testinde izlenen allo-antikor pozitifliği de hastanın geçmişte yaptığı doğumlar sırasında oluşan alloimmünizasyon ile açıklanabilir.

Olgumuzda kemoterapi protokolünün bir parçası olarak oksaliplatin ile eşzamanlı uygulanan 5-florourasil, folinik asit, bevasizumab ve diğer destek tedavilerinin de ilaç ilişkili OİHA'ya sebep olma olasılığı ileri sürülebilir. Ancak mevcut literatürde FOLFOX komoterapi protokolü uygulanan bir hastada gelişen OİHA tablosunu 5-florourasil ile ilişkilendiren tek bir olgu sunumu dışında 5florourasil, folinik asit veya bevasizumab ile OİHA ilişkisini bildiren başka yayın bulunmamaktadır (7). 
$\mathrm{Bu}$ olguda oksaliplatin ilişkili OİHA'nın ayırıcı tanısında idiyopatik sicak OİHA'nın yanı sira altta yatan romatolojik hastalıklar ve paraneoplastik süreçler gibi olası sekonder sebepler de göz önünde bulundurulmalıdır. Olgunun 10 aylık takibinde ortaya çıan herhangi bir romatolojik semptom ve/veya bulgu izlenmemiştir. Kolon kanseri ve OİHA birlikteliği ilk kez 1974'te otopsi ile tanı konmuş bir kolon kanseri olgusunda bildirilmiştir ve seyrek olarak görülmektedir (13). Yakın zamandaki bir derlemede 19452009 yılları arasında yayımlanan ve MEDLINE veritabanında yer alan 52 paraneoplastik OİHA olgusunumu arasından sadece beşinin kolon kanseri ilişkili olduğu ve bunların sadece ikisinde sıcak OİHA izlendiği bildirilmiştir (14).

Oksaliplatin ilişkili OİHA'nın tedavisinde ilk basamak oksaliplatinin kesilerek bundan sonra verilecek olan tedavilerden tamamen çıkarılmasıdır $(11,12)$. Ilımlı seyreden olgular sadece transfüzyon desteği ile takip edilebilirken olguların çoğunda steroid tedavisi gerekli olmaktadır (12). Steroid tedavisine yanıt iyi olup genellikle 2-4 hafta içinde tamamen düzelme sağlanmaktadır (11). Genel ilke olarak hemoglobin düzeyleri normale dönene ve direk Coombs testi negatifleşene kadar doz azaltımı yapılmaksızın steroid tedavisine devam edilmeli; yanıt alındıktan sonra steroid dozu tedricen azaltılarak kesilmelidir. Plazmaferez ve intravenözimmünglobulin (IVIg) steroid tedavisine yanit vermeyen veya bizim olgumuz gibi şiddetli akut hemoliz bulgularıla seyreden hastalarda kullanılabilir (11).

Özetle, oksaliplatin ilişkili OİHA nadir görülen ve genellikle tekrarlanan oksaliplatin dozları sonrası tedavinin geç döneminde ortaya çıkan, şiddetli akut intravasküler hemolize sebep olarak morbidite ve hatta mortaliteye yol açabilen, ancak tedavi yanıtı genellikle iyi olan ciddi bir klinik tablodur. Risk altında olan hasta grubu günlük klinik uygulamalarda bu komplikasyonun gelişimi açısından dikkatle izlenmelidir.

\section{Çıkar çatışması: Yok}

\section{Referanslar}

1. Cassidy J, Tabernero J, Twelves C, Brunet R, Butts C, Conroy T, et al. XELOX (capecitabine plus oxaliplatin): active first-line therapy for patients with metastatic colorectal cancer. J Clin Oncol. 2004;22(11):2084-91.

2. Scheithauer W, Kornek GV, Raderer M, Schull B, Schmid K, Kovats E, et al. Randomized multicenter phase II trial of two different schedules of capecitabine plus oxaliplatin as first-line treatment in advanced colorectal cancer. J Clin Oncol. 2003;21(7):1307-12.

3. Meng L, Romano A, Smith E, Macik G, Grosh WW. Disseminated intravascular coagulation and immune hemolytic anemia, possibly Evans syndrome, after oxaliplatin and bevacizumab infusion for metastatic colon adenocarcinoma: a case report and literature review. Clin Colorectal Cancer. 2015;14(1):e1-3.

4. Garbe E, Andersohn F, Bronder E, Klimpel A, Thomae M, Schrezenmeier H, et al. Drug induced immune haemolytic anaemia in the Berlin CaseControl Surveillance Study. British journal of haematology. 2011;154(5):644-53.

5. Ulusakarya A, Misra S, Haydar M, Habert $H$, Castagne V, Gumus Y, et al. Acute renal failure related to oxaliplatin-induced intravascular hemolysis. Med Oncol. 2010;27(4):1425-6.

6. Mayer B, Bartolmas T, Yurek S, Salama A. Variability of Findings in Drug-Induced Immune Haemolytic Anaemia: Experience over 20 Years in a Single Centre. Transfus Med Hemother. 2015;42(5):333-9.

7. Yurek S, Riess H, Kreher S, Dorken B, Salama A. Fatal immune haemolysis due to antibodies to individual metabolites of 5-fluorouracil. Transfus Med. 2010;20(4):265-8.

8. Garratty G. Immune hemolytic anemia associated with drug therapy. Blood Rev. 2010;24(4-5):143-50.

9. Desrame J, Broustet H, Darodes de Tailly P, Girard D, Saissy JM. Oxaliplatin-induced haemolytic anaemia. Lancet. 1999;354(9185):1179-80.

10. Salama A. Drug-induced immune hemolytic anemia. Expert Opin Drug Saf. 2009;8(1):73-9.

11. Polyzos A, Tsavaris N, Gogas H, Souglakos J, Vambakas L, Vardakas N, et al. Clinical features of hypersensitivity reactions to oxaliplatin: a 10 -year experience. Oncology. 2009;76(1):36-41.

12. Forcello NP, Khubchandani S, Patel SJ, Brahaj D. Oxaliplatin-induced immune-mediated cytopenias: a case report and literature review. J Oncol Pharm Pract. 2015;21(2):148-56.

13. Miura AB, Shibata A, Akihama T, Endo Y, Sugawara M. Autoimmune hemolytic anemia associated with colon cancer. Cancer. 1974;33(1):111-4.

14. Puthenparambil J, Lechner K, Kornek G. Autoimmune hemolytic anemia as a paraneoplastic phenomenon in solid tumors: A critical analysis of 52 cases reported in the literature. Wien Klin Wochenschr. 2010;122(7-8):229-36. 